\title{
Prognostic value of non-sustained ventricular tachycardia and the potential role of amiodarone treatment in hypertrophic cardiomyopathy: assessment in an unselected non-referral based patient population
}

\author{
F Cecchi, I Olivotto, A Montereggi, G Squillatini, A Dolara, B J Maron
}

\begin{abstract}
Background-Amiodarone has been reported to reduce the likelihood of sudden death in patients with hypertrophic cardiomyopathy (HCM). However, data regarding the clinical course in HCM have traditionally come from selected referral populations biased toward assessment of high risk patients.

Aims-To evaluate antiarrhythmic treatment for sudden death in an HCM population not subject to tertiary referral bias, closely resembling the true disease state present in the community.

Methods-Cardiovascular mortality was assessed in relation to the occurrence of non-sustained ventricular tachycardia (NSVT) on 24 or 48 hour ambulatory Holter recording, a finding previously regarded as a marker for sudden death, particularly when the arrhythmia was frequent, repetitive or prolonged. 167 consecutive patients were analysed by multiple Holter ECG recordings (mean (SD) 157 (129) hours) and followed for a mean of 10 (5) years. Only patients with multiple repetitive NSVT were treated with amiodarone, and in relatively low doses (220 (44) mg/day).
\end{abstract}

Results-Nine HCM related deaths occurred: 8 were the consequence of congestive heart failure, but only 1 was sudden and unexpected. Three groups of patients were segregated based on their NSVT profile: group 1 ( $n=39$ ), multiple ( $\geqslant 2$ runs) and repetitive bursts (on $\geqslant 2$ Holters) of NSVT, or prolonged runs of ventricular tachycardia, included 4 deaths due to heart failure; group $2(n=38)$, isolated infrequent bursts of NSVT, included 1 sudden death; group $3(n=90)$, without NSVT, included 4 heart failure deaths. Kaplan-Meier survival analysis showed no significant differences in survival between the three groups throughout follow up.

Conclusions-In an unselected patient population with HCM, isolated, nonrepetitive bursts of NSVT were not associated with adverse prognosis and so this arrhythmia does not appear to justify chronic antiarrhythmic treatment. Amiodarone, administered in relatively low doses, did not carry an independent and additive risk for cardiac mortality. Amiodarone may have contributed to the absence of sudden cardiac death in patients believed to be at higher risk because of multiple repetitive NSVT.

(Heart 1998;79:331-336)

Keywords: hypertrophic cardiomyopathy; ventricular tachycardia; amiodarone

Stratification of risk and treatment to prevent sudden cardiac death in patients with hypertrophic cardiomyopathy (HCM) has generated considerable investigation and controversy. ${ }^{1-17}$ Previous studies from tertiary referral centres have reported an association between nonsustained ventricular tachycardia (NSVT) and sudden cardiac death in patients with HCM, in whom the detection of isolated NSVT had low positive but high negative predictive value for sudden death. ${ }^{8-21}$ However, it is possible that NSVT may not bear the same prognostic significance in unselected patient groups that more closely resemble the true HCM disease state. ${ }^{22-27}$ In addition, in one investigation, the likelihood for sudden death was reduced in patients with HCM and NSVT to whom relatively low dose amiodarone was administered. ${ }^{21}$ Other investigators have questioned the safety of amiodarone treatment in $\mathrm{HCM}^{28}$ Nevertheless, based on the initial enthusiasm for amiodarone as treatment for patients with HCM and NSVT perceived at increased for sudden death, we applied the principles of risk stratification and treatment of McKenna and colleagues ${ }^{202129} 30$ to our patients with this disease. The present study was done to assess our clinical experience in a large non-referral based HCM population, with regard to the safety and the potential benefits of long term amiodarone treatment for risk reduction.

\section{Methods}

PATIENT SELECTION

Between 1980 and 1992, 202 consecutive patients diagnosed with HCM at Cardiologia di S Luca, Ospedale di Careggi in Florence, Italy were evaluated clinically on more than two occasions and followed for more than one year. ${ }^{23}$ Of the 202 patients, 12 refused Holter recording and were excluded from analysis; we chose to exclude 23 further patients because they had been treated with amiodarone for atrial fibrillation rather than NSVT. The remaining 167 patients constitute the final study group. Patients were followed for 1 to 30 
years (mean (SD) 10 (5)) from the time of initial HCM diagnosis, and were evaluated longitudinally in a standard fashion at about yearly intervals with clinical examination, 12 lead ECG, cross sectional echocardiogram, treadmill exercise test, and ambulatory Holter monitoring. Diagnostic and management strategies were generally consistent during the follow up period, with one investigator assuming primary responsibility for each patient. The diagnosis of HCM was based on echocardiographic identification of a hypertrophied and non-dilated left ventricle in the absence of other cardiac or systemic disease capable of producing the magnitude of left ventricular hypertrophy present in that patient. ${ }^{131}$

HOLTER ECG MONITORING

Continuous Holter recordings were obtained using commercially available portable equipment (Avionics, Irvine, California, USA) with two leads (V1 and V5). Patients were instructed to complete a diary and activate the event marker should they have symptoms. Each of the 167 patients had routine 24 or 48 hour ambulatory Holter ECG (range, 1-18 times). Additional recordings were obtained as dictated by clinical events (such as increasing symptoms or occurrence of syncope or angina) or by the presence of NSVT (which itself dictated subsequent Holter ECGs within the ensuing month), as well as to evaluate the suppression of arrhythmias by amiodarone. The mean (SD) elapsed Holter recording time in our study patients was 157 (129) hours. NSVT was defined as self terminating bursts of $>3$ consecutive extrasystoles with a heart rate $>120$ beats $/ \mathrm{min} .{ }^{21}$ Isolated infrequent NSVT was defined as one burst only of NSVT over a 24 hour period on one or more Holter recordings; multiple repetitive NSVT was defined as two or more bursts on one or more Holters.

ECHOCARDIOGRAPHY

Echocardiographic studies were performed with Toshiba $65 \mathrm{~A}$ and 270 instruments, using 2.5 and $3.75 \mathrm{MHz}$ transducers. Extent and distribution of left ventricular hypertrophy was assessed as described previously. ${ }^{31}{ }^{32}$ Magnitude of left ventricular outflow tract gradient under basal conditions was estimated with continuous wave Doppler. ${ }^{33}$

STATISTICAL ANALYSIS

Data were expressed as mean (SD). Statistical analyses were performed using unpaired Student's $t$ test for the comparison of normally distributed data. Fisher's exact test or $\chi^{2}$ test were used where appropriate to compare noncontinuous variables expressed as proportions. Survival and event-free curves were calculated using Kaplan-Meier estimates. ${ }^{34}$

\section{Results}

DEMOGRAPHIC, CLINICAL, AND

ECHOCARDIOGRAPHIC CHARACTERISATION

Ages of the 167 study patients at the time of initial evaluation were 14-74 years (mean 41 (16)); 116 patients (69\%) were men. At most recent evaluation, 74 patients were asympto-

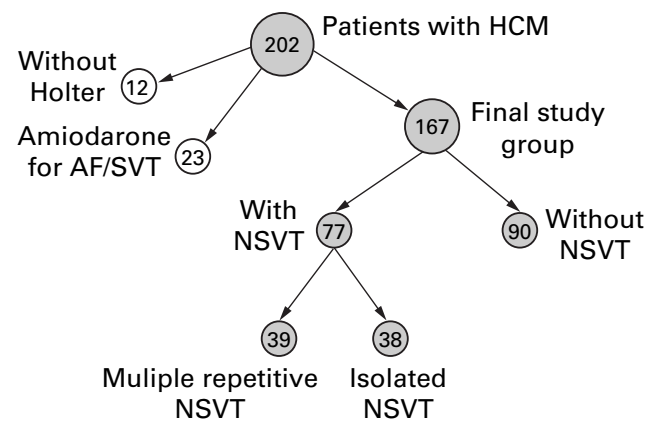

Figure 1 Flow diagram showing the three groups identified among the 202 HCM patients based on ambulatory Holter ECG findings. AF, atrial fibrillation; SVT supraventricular tachycardia; NSVT, non-sustained ventricular tachycardia.

matic, 60 had experienced mild symptoms (New York Heart Association (NYHA) class II), and 33 had severe symptoms (NYHA class III-IV); six of the last 33 patients appeared to have morphological and functional evidence of the end stage phase of HCM. ${ }^{35}$

Echocardiography showed maximal left ventricular thicknesses of 13-41 mm (mean 23 (5)). Patterns and distribution of left ventricular wall thickening involved substantial portions of both ventricular septum and free wall in 102 patients $(61 \%)$, anterior and posterior septum alone in 25 patients (15\%), anterior septum only in 23 patients (14\%), and portions of left ventricle other than anterior septum in 17 patients $(10 \%) .^{31}$ Left ventricular end diastolic cavity dimension was $35-60 \mathrm{~mm}$ (mean 43 (6)), left atrium was $32-52 \mathrm{~mm}$ (mean 41 (8)), and percentage fractional shortening was $20-61 \%$ (mean 39 (8)). Basal left ventricular outflow tract obstruction (> $30 \mathrm{~mm} \mathrm{Hg}$ ) was documented by continuous wave Doppler ${ }^{33}$ in 33 patients (20\%).

IDENTIFICATION OF NON-SUSTAINED

VENTRICULAR TACHYCARDIA

Of the 167 study patients, 90 (54\%) did not have ventricular tachycardia on Holter monitoring. The remaining 77 patients $(46 \%)$ had $\geqslant 1$ bursts of NSVT on $\geqslant 1$ Holter recording (fig 1). Of these 77 patients, 38 had isolated infrequent NSVT and 39 had multiple repetitive NSVT, or prolonged runs of ventricular tachycardia (identified in two patients with self terminated periods of 25 and 36 seconds) (fig 1 , table 1 ).

The number of runs of NSVT ranged from 1 to 29 during a single Holter ECG recording period at ventricular rates of 120 to 175 beats/ min. For the group with isolated infrequent NSVT, in 35 patients (92\%) runs did not exceed five consecutive beats (mean 3 (2)). For the group with multiple repetitive NSVT, the number of beats comprising the longest run in each patient ranged from 3 to 72 (mean 9 (15)), with most of these being brief (3-5 beats).

MEDICAL TREATMENT

In the 39 patients with multiple repetitive runs of NSVT (or long runs of ventricular tachycardia) on Holter ECG, amiodarone was given as 
Table 1 Demographic, clinical, and morphological data of 167 patients with hypertrophic cardiomyopathy divided on the basis of non-sustained ventricular tachycardia on ambulatory Holter ECG

\begin{tabular}{|c|c|c|c|c|c|c|c|c|c|c|c|c|c|c|c|c|c|c|}
\hline \multirow[b]{2}{*}{$\begin{array}{l}\text { Group } \\
(n)\end{array}$} & \multirow[b]{2}{*}{$\begin{array}{l}\text { Age at } \\
\text { Dx } \\
\text { (years) }\end{array}$} & \multicolumn{4}{|c|}{ NYHA functional class } & \multirow[b]{2}{*}{$\begin{array}{l}L A \\
(\mathrm{~mm})\end{array}$} & \multirow[b]{2}{*}{$\begin{array}{l}L V \\
\max \\
(\mathrm{mm})\end{array}$} & \multirow[b]{2}{*}{$\begin{array}{l}\text { LVOT } \\
(>30)\end{array}$} & \multirow[b]{2}{*}{$A F$} & \multirow[b]{2}{*}{ Syncope } & \multicolumn{3}{|c|}{ Treatment } & \multicolumn{2}{|c|}{$\begin{array}{l}\text { Follow up } \\
\text { (years) }\end{array}$} & \multicolumn{3}{|c|}{$\begin{array}{l}\text { Cardiovascular } \\
\text { deaths }\end{array}$} \\
\hline & & Initial & $\begin{array}{l}\text { Most } \\
\text { recent }\end{array}$ & $\begin{array}{l}\text { I-II } \\
\text { (initial) }\end{array}$ & $\begin{array}{l}I-I I \\
\text { (final) }\end{array}$ & & & & & & $\begin{array}{l}\beta \\
\text { blockers }\end{array}$ & $\begin{array}{l}\text { Ca } \\
\text { channel } \\
\text { blockers }\end{array}$ & Diuretics & $\begin{array}{l}\text { After } \\
D x\end{array}$ & $\begin{array}{l}\text { After } \\
\text { NSVT }\end{array}$ & All & $S D$ & $C H F$ \\
\hline $1(39)$ & $\begin{array}{l}49 \\
(14)^{\star}\end{array}$ & $\begin{array}{l}1.9 \\
(0.8)^{\star}\end{array}$ & $\begin{array}{l}2.3 \\
(0.8) \neq \S\end{array}$ & $\begin{array}{l}32 \\
(82 \%)\end{array}$ & $\begin{array}{l}25 \\
(64 \%)\end{array}$ & $\begin{array}{l}46 \\
(8)^{\star}\end{array}$ & $\begin{array}{l}25 \\
(5) \ddagger\end{array}$ & $\begin{array}{l}15 \\
(38 \%) \neq \S\end{array}$ & $\begin{array}{l}18 \\
(46 \%) \ddagger \varnothing\end{array}$ & $\begin{array}{l}10 \\
(26 \%) \dagger\end{array}$ & $\begin{array}{l}24 \\
(61 \%)\end{array}$ & $\begin{array}{l}18 \\
(46 \%)\end{array}$ & $\begin{array}{l}11 \\
(28 \%) \ddagger\end{array}$ & $\begin{array}{l}11 \\
(5)\end{array}$ & $\begin{array}{l}6.1 \\
(2.8)\end{array}$ & $\begin{array}{l}4 \\
(13 \%)\end{array}$ & 0 & 4 \\
\hline $2(38)$ & $\begin{array}{l}39 \\
(17)\end{array}$ & $\begin{array}{l}1.4 \\
(0.7)\end{array}$ & $\begin{array}{l}1.8 \\
(0.8)\end{array}$ & $\begin{array}{l}34 \\
(90 \%)\end{array}$ & $\begin{array}{l}27 \\
(71 \%)\end{array}$ & $\begin{array}{l}41 \\
(8)\end{array}$ & $\begin{array}{l}23 \\
(5)\end{array}$ & $\begin{array}{l}5 \\
(13 \%)\end{array}$ & $\begin{array}{l}9 \\
(24 \%)\end{array}$ & $3(8 \%)$ & $\begin{array}{l}22 \\
(56 \%)\end{array}$ & $\begin{array}{l}17 \\
(44 \%)\end{array}$ & $\begin{array}{l}9 \\
(23 \%)\end{array}$ & $\begin{array}{l}11 \\
(6)\end{array}$ & $\begin{array}{l}6.0 \\
(2.6)\end{array}$ & 1 & 1 & 0 \\
\hline $3(90)$ & $\begin{array}{l}40 \\
(16)\end{array}$ & $\begin{array}{l}1.6 \\
(0.6)\end{array}$ & $\begin{array}{l}1.7 \\
(0.7)\end{array}$ & $\begin{array}{l}88 \\
(98 \%) \dagger\end{array}$ & $\begin{array}{l}82 \\
(91 \%)^{\star}\end{array}$ & $\begin{array}{l}39 \\
(7)\end{array}$ & $\begin{array}{l}22 \\
(5)\end{array}$ & $\begin{array}{l}13 \\
(14 \%)\end{array}$ & $\begin{array}{l}10 \\
(11 \%)\end{array}$ & $\begin{array}{l}9 \\
(10 \%)\end{array}$ & $\begin{array}{l}31 \\
(34 \%) \dagger\end{array}$ & $\begin{array}{l}32 \\
(36 \%)\end{array}$ & $\begin{array}{l}10 \\
(11 \%)\end{array}$ & $9(5)$ & - & $\begin{array}{l}4 \\
(4 \%)\end{array}$ & 0 & 4 \\
\hline $\begin{array}{l}\text { Total } \\
\quad(167)\end{array}$ & $\begin{array}{l}41 \\
(16)\end{array}$ & $\begin{array}{l}1.6 \\
(0.7)\end{array}$ & $\begin{array}{l}1.8 \\
(0.8)\end{array}$ & $\begin{array}{l}154 \\
(92 \%) \dagger\end{array}$ & $\begin{array}{l}134 \\
(80 \%)^{\star}\end{array}$ & $\begin{array}{l}41 \\
(8)\end{array}$ & $\begin{array}{l}23 \\
(5)\end{array}$ & $\begin{array}{l}33 \\
(20 \%)\end{array}$ & $\begin{array}{l}37 \\
(22 \%)\end{array}$ & $\begin{array}{l}22 \\
(13 \%)\end{array}$ & $\begin{array}{l}77 \\
(46 \%)\end{array}$ & $\begin{array}{l}67 \\
(40 \%)\end{array}$ & $\begin{array}{l}30 \\
(18 \%)\end{array}$ & $\begin{array}{l}10 \\
(5)\end{array}$ & $\begin{array}{l}6.1 \\
(2.7)\end{array}$ & $\begin{array}{l}9 \\
(5 \%)\end{array}$ & 1 & 8 \\
\hline
\end{tabular}

Group 1, multiple repetitive NSVT; Group 2, isolated NSVT; Group 3, no NSVT.

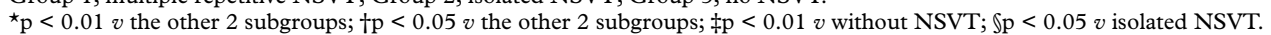

NYHA, New York Heart Association functional class; LA, left atrium; LV max, maximum left ventricular thickness; LVOT, left ventricular outflow tract gradient ( $>30 \mathrm{~mm} \mathrm{Hg}$; estimated with continuous wave Doppler echocardiography ${ }^{33}$ ); AF, atrial fibrillation; CHF, congestive heart failure; Dx, diagnosis; SD, sudden (cardiac) death.

Table 2 Demographic, clinical, and morphological data of the nine patients with hypertrophic cardiomyopathy related death

\begin{tabular}{|c|c|c|c|c|c|c|c|c|c|c|c|c|c|c|c|c|c|c|}
\hline \multirow[b]{2}{*}{ Patient } & \multirow[b]{2}{*}{ Sex } & \multirow[b]{2}{*}{ NSVT } & \multirow[b]{2}{*}{$\begin{array}{l}\text { Age at } \\
D x \\
\text { (years) }\end{array}$} & \multirow[b]{2}{*}{$\begin{array}{l}\text { Age at } \\
\text { death } \\
\text { (years) }\end{array}$} & \multirow[b]{2}{*}{$\begin{array}{l}\text { Follow } \\
\text { up } \\
\text { (years) }\end{array}$} & \multirow{2}{*}{$\begin{array}{l}\text { NSVT } \\
\text { to } \\
\text { death } \\
\text { (years) }\end{array}$} & \multirow[b]{2}{*}{$\begin{array}{l}\text { Family } \\
\text { history }\end{array}$} & \multicolumn{2}{|c|}{ NYHA class } & \multirow[b]{2}{*}{$\begin{array}{l}L V W T \\
\max \\
(\mathrm{mm})\end{array}$} & \multirow[b]{2}{*}{$\begin{array}{l}L A \\
(\mathrm{~mm})\end{array}$} & \multirow[b]{2}{*}{$\begin{array}{l}\text { LVED } \\
(\mathrm{mm})\end{array}$} & \multirow[b]{2}{*}{$\begin{array}{l}F S \\
(\%)\end{array}$} & \multirow[b]{2}{*}{$\begin{array}{l}\text { Basal } \\
\text { LVOTG } \\
(m m \mathrm{Hg})\end{array}$} & \multirow[b]{2}{*}{$\begin{array}{l}P A P \\
(m m H g) \\
S / D\end{array}$} & \multirow[b]{2}{*}{$A F$} & \multirow[b]{2}{*}{$\begin{array}{l}\text { End } \\
\text { stage } \\
H_{C M} M^{*}\end{array}$} & \multirow[b]{2}{*}{$\begin{array}{l}\text { Cause of } \\
\text { death }\end{array}$} \\
\hline & & & & & & & & Initial & $\begin{array}{l}\text { Most } \\
\text { recent }\end{array}$ & & & & & & & & & \\
\hline 1 & $\mathrm{M}$ & None & 40 & 53 & 12.7 & - & $\begin{array}{l}\mathrm{HCM}+ \\
\mathrm{SD}\end{array}$ & II & IV & 30 & 52 & 41 & 29 & 32 & $55 / 25$ & $\mathrm{C}$ & + & $\mathrm{CHF}$ \\
\hline 2 & $\mathrm{~F}$ & None & 59 & 72 & 13.1 & - & $\begin{array}{l}\mathrm{HCM}+ \\
\mathrm{SD}\end{array}$ & IV & III & 30 & 40 & 43 & 25 & 100 & $42 / 14$ & C & + & $\begin{array}{l}\mathrm{CHF} / \\
\text { stroke }\end{array}$ \\
\hline 3 & M & None & 60 & 73 & 12.8 & - & 0 & II & III & 28 & 53 & 48 & 41 & 0 & - & 0 & 0 & $\mathrm{CHF}$ \\
\hline 4 & $\mathrm{~F}$ & None & 66 & 75 & 8.8 & - & $\mathrm{HCM}$ & IV & IV & 30 & 70 & 26 & 61 & 0 & $75 / 40$ & $\mathrm{C}$ & 0 & $\mathrm{CHF}$ \\
\hline 5 & $\mathrm{~F}$ & Iso & 25 & 48 & 23.2 & 15.2 & 0 & II & II & 26 & 53 & 40 & 24 & 100 & $52 / 12$ & $\mathrm{P}$ & 0 & SD \\
\hline 6 & M & MR & 30 & 31 & 1.0 & 1.0 & 0 & III & III & 24 & 49 & 41 & 39 & 60 & $60 / 34$ & 0 & 0 & $\mathrm{CHF}$ \\
\hline 7 & M & MR & 20 & 48 & 28.0 & 26.5 & $\begin{array}{l}\mathrm{HCM}+ \\
\mathrm{SD}\end{array}$ & I & IV & 23 & 43 & 45 & 38 & 0 & - & $\mathrm{C}$ & + & $\mathrm{CHF}$ \\
\hline 8 & M & MR & 59 & 62 & 3.8 & 3.8 & 0 & II & III & 26 & 50 & 44 & 32 & 0 & - & C & + & $\begin{array}{l}\mathrm{CHF} / \\
\text { stroke }\end{array}$ \\
\hline 9 & $\mathrm{~F}$ & MR & 70 & 73 & 2.8 & 2.8 & 0 & II & III & 28 & 47 & 27 & 22 & 100 & - & 0 & 0 & $\mathrm{CHF}$ \\
\hline
\end{tabular}

-, data not available; + , present; 0 , absent; ${ }^{\star}$, defined as severe progressive heart failure associated with left ventricular wall thinning (with or without asynergy), relative cavity enlargement, decreased ejection fraction or any combination of these.

$\mathrm{AF}$, atrial fibrillation; C, chronic; CHF, congestive heart failure; Dx, diagnosis; Hx, history; Iso, Isolated; LA, left atrium; LVWT, left ventricular wall thickness; LVED, left ventricular end diastolic dimension; LVOTG, left ventricular outflow tract pressure gradient estimated with continuous wave Doppler echocardiography ${ }^{33}$; MR, multiple repetitive; $\mathrm{P}$, paroxysmal; PAP (S/D), pulmonary arterial pressure (systolic/diastolic); SD, sudden death; FS, fractional shortening.

proposed by McKenna et al. ${ }^{21} 3637$ Briefly, we used a loading dose of $600 \mathrm{mg} /$ day for the first week, followed by $200-400 \mathrm{mg} /$ day for the following four weeks. A maintenance dose of $150-400 \mathrm{mg} /$ day was then adjusted to maintain a QTc interval of $460-480 \mathrm{~ms}^{38}$ Mean (SD) maintenance dose was 220 (44) $\mathrm{mg} /$ day. The 39 patients took amiodarone for $>75 \%$ of the period of follow up after the demonstration of multiple repetitive NSVT on Holter monitoring; duration of treatment ranged from eight months to seven years (mean 4 (2) years). Ten of the 39 patients stopped amiodarone treatment at the end of the follow up period because of relatively mild and reversible side effects (such as alterations of thyroid function and amiodarone induced bradycardia).

By design, the 38 patients with isolated infrequent NSVT on Holter monitoring did not automatically receive antiarrhythmic treatment; however, six of these patients had clinically indicated drug treatment for atrial fibrillation or other supraventricular arrhythmias with propafenone and quinidine.

The 90 patients without NSVT on Holter ECG did not receive specific antiarrhythmic treatment. Of the 167 study patients, 122 received other standard cardioactive drugs, primarily for the treatment of congestive symp- toms, including $\beta$ blockers (63 patients), calcium channel blockers (59 patients), or diuretics (30 patients) administered in a virtually continuous fashion and in standard dosages. ${ }^{23}$

\section{CLINICAL OUTCOME}

Of the 167 study patients, nine (8\%) died of cardiovascular causes related to HCM during the follow up period (table 2). Of these, eight had progressive severe heart failure and functional limitation that led directly to their death, including four patients with features of the end stage phase of HCM (table 2). ${ }^{35}$ The remaining patient, who was mildly symptomatic, died suddenly and unexpectedly at 47 years of age. The nine patients who died were distributed among the three patient groupsfour deaths from heart failure among the 39 patients with multiple repetitive NSVT; one sudden death in the 38 patients with isolated infrequent bursts of NSVT; four deaths from heart failure among the 90 patients without NSVT (table 1). Of note, both patients with prolonged runs of ventricular tachycardia have survived to date.

Kaplan-Meier analysis showed no significant difference in survival (from the time of diagnosis) between the three groups of patients (fig 2). When survival was assessed specifically for the 


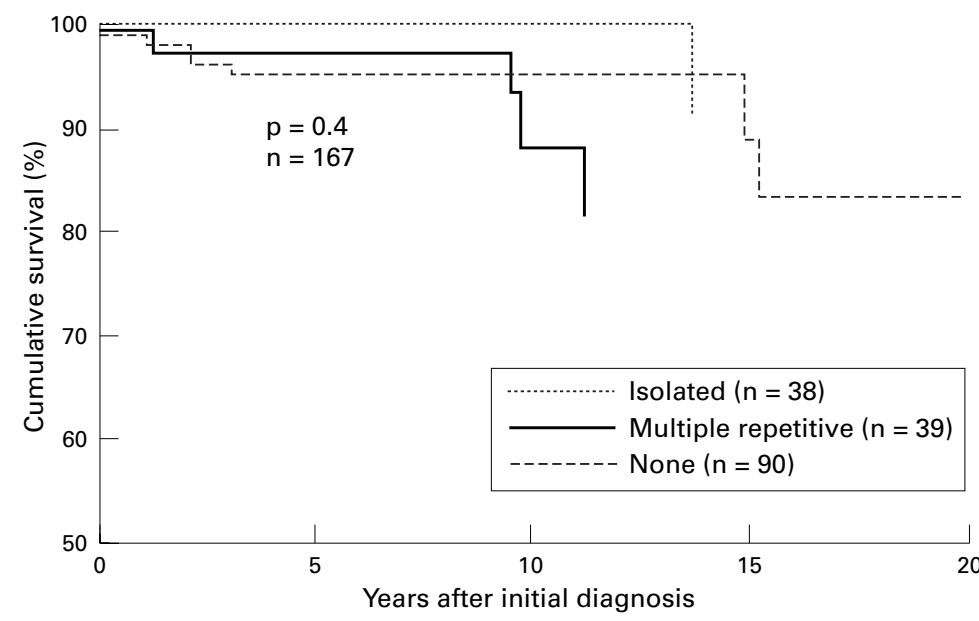

Figure 2 Kaplan-Meier estimates of cumulative survival during the period of follow up from the time of initial diagnosis of HCM in the three patient groups. There was no significant difference in survival between the three groups independent of whether a pooled or pairwise analysis was performed (cumulative $p$ value was 0.4 ; for all pairwise comparisons, $p$ was $>0.1$ ). period of time following initial detection of NSVT there was no difference in cardiovascular mortality between patients with isolated infrequent NSVT and multiple repetitive $\operatorname{NSVT}(p=0.2)($ fig 3$)$.

CLINICAL DEMOGRAPHICS OF PATIENT GROUPS Table 1 summarises the clinical and demographic findings in the three patient groups. Compared with the two other groups, the 39 patients with multiple repetitive bursts of NSVT were older and showed greater functional impairment and left atrial dimension, as well as more frequent occurrence of basal outflow tract obstruction, syncope, and new episodes of atrial fibrillation. The 90 patients without NSVT and the 38 patients with isolated infrequent NSVT were similar with respect to these clinical and morphological variables.

\section{Discussion}

Sudden and unexpected death is the most devastating feature of the natural history of HCM, but the stratification of risk in patients with this disease has proved challenging. ${ }^{1-17}$ Indeed, most patients who experience sudden cardiac death are asymptomatic (or mildly symptomatic), and cardiovascular collapse may be the first clinical manifestation of disease. $^{611131417}$ As it is apparent that only a small proportion of patients within the broad disease spectrum of HCM are at increased risk for sudden death, there has been considerable interest in the identification of such groups, so that treatment strategies can be selectively implemented. ${ }^{14-17}$

The presence of short bursts of NSVT on ambulatory Holter ECG has previously been suggested as a risk factor for sudden death in adult patients with HCM, based primarily on screening studies using highly selected patients from tertiary referral centres. ${ }^{18-20}$ In this regard, McKenna and colleagues ${ }^{21}$ proposed the administration of amiodarone in relatively low doses to prevent sudden death in patients with HCM and NSVT. In a non-randomised study

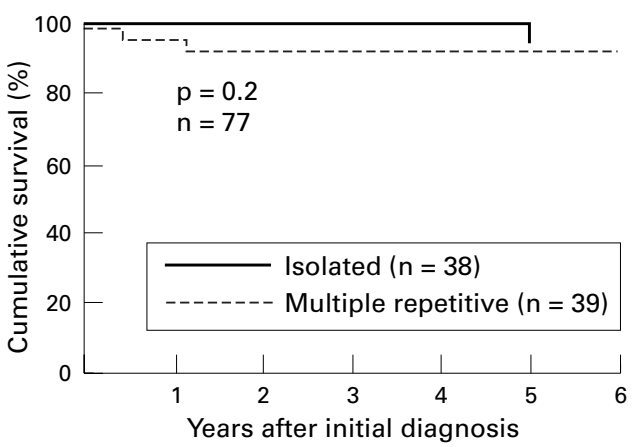

Figure 3 Kaplan-Meier estimates of cumulative survival during the period following the first detection of NSVT in 77 study patients. Survival did not differ significantly $(p=0.2)$ between patients with isolated infrequent NSVT receiving no systematic antiarrhythmic treatment from those with multiple repetitive NSVT treated with amiodarone.

design, these investigators showed improved survival in patients with ventricular tachycardia treated with amiodarone compared to a matched control group of patients with this disease who received treatment with class I antiarrhythmic agents, primarily quinidine and $\beta$ blockers. ${ }^{21}$ More recently, other investigators have suggested that the significance of NSVT as a marker for sudden cardiac death may not be the same in HCM populations relatively free from selection bias, ${ }^{22}$ compared to tertiary referral populations comprised largely of patients selected because they had already been judged to be at increased risk..$^{22-27}$ For example, in $151 \mathrm{HCM}$ patients from a cohort evaluated at both referral and non-referral Italian institutions, Spirito and colleagues ${ }^{22}$ reported brief and infrequent bursts of NSVT to be associated with low cardiac mortality in asymptomatic (or mildly symptomatic) patients, and suggested that such ventricular arrhythmias themselves probably should not be an indication for antiarrhythmic treatment.

In the present study, we chose to address this important question further in an unselected population of HCM patients from the Tuscany region of central Italy, judged to be representative of the overall disease spectrum and having a clinical follow up of up to 30 years. ${ }^{23}$ We divided our study patients into three groups based on the findings of ambulatory Holter ECGs obtained in a clinical context periodically during follow up: group 1, patients with multiple repetitive NSVT; group 2, patients with isolated infrequent bursts of NSVT; and group 3, patients without NSVT. Our patients with multiple repetitive NSVT were judged to be at potentially higher risk of sudden death and over the past 10 years have been consistently treated with amiodarone in relatively low doses (150-400 mg/day), according to the recommendations of McKenna and associates. ${ }^{213637}$ Conversely, such preventive antiarrhythmic treatment with amiodarone was not given to the patients with isolated infrequent bursts of NSVT. Of note, during the follow up period, there were no significant differences in total HCM related mortality between the three groups of patients divided on the basis of the presence or frequency of NSVT. Thus, we believe that it is reasonable to 
conclude that bursts of NSVT, when isolated and brief, are not an unfavourable long term prognostic feature in patients with $\mathrm{HCM}^{22}$ Consequently, it is probably not necessary (nor prudent) to administer long term amiodarone treatment based solely on the finding of isolated infrequent bursts of NSVT on Holter ECG.

One of our 38 patients with isolated infrequent NSVT died suddenly and unexpectedly at age 48; however, this occurred 10 years after the first (and only) detection of NSVT. There were no sudden and unexpected deaths among the 39 patients with multiple repetitive NSVT (all of whom received amiodarone), although four of these patients died because of HCM related progressive heart failure.

We cannot be absolutely certain to what extent the absence of sudden cardiac death in our patients with multiple repetitive NSVT can be attributed solely to the administration of amiodarone. First, this study was based on the clinical perception that repetitive NSVT confers greater risk than isolated bursts of NSVT in patients with HCM; this view is based on reasonable inferences previously proposed for $\mathrm{HCM}^{22}{ }^{39}$ as well as for coronary artery disease, ${ }^{40}$ but as yet is unproved. Moreover, the relatively low event rate for sudden catastrophes in unselected HCM populations such as ours has been emphasised previously, ${ }^{22-27}$ and this fact alone could account in large part for our findings. We favour the view that amiodarone treatment itself may have played a role in determining the favourable clinical outcome and preventing sudden unexpected cardiac death in the present study population. Indeed, apart from the potential role of amiodarone in suppressing ventricular tachyarrhythmias ${ }^{41} 42$ and possibly reducing the risk for sudden death in $\mathrm{HCM},{ }^{21}$ it is also conceivable that it exerted a similar beneficial effect on atrial fibrillation, known to be an important predictor of cardiovascular mortality in HCM. ${ }^{1} 2023$

It has previously been suggested that amiodarone administration is associated with increased mortality from sudden death in HCM patients treated for severe and refractory congestive symptoms. ${ }^{28}$ However, we found little evidence that amiodarone adversely affected the long term prognosis of our patients in such a fashion. Indeed, in the patient subset with multiple repetitive NSVT (all of whom received amiodarone), excess cardiovascular mortality was not evident, even though the patients receiving that drug were significantly older and generally had more severe disease. One possible explanation for such conflicting views regarding the safety of amiodarone in HCM may lie with differences in drug dosage. In the present study, as well as that of McKenna et $a l,^{21}$ directed largely towards treatment of asymptomatic (or mildly symptomatic) patients judged to be at increased risk of sudden death due to NSVT on Holter ECG, the daily maintenance dose of amiodarone was about $200 \mathrm{mg} /$ day. ${ }^{21}$ In contrast, investigators describing increased mortality associated with amiodarone used particularly high loading (up to $1600 \mathrm{mg} /$ day) and maintenance $(400 \mathrm{mg}$ / day) doses, almost twice that administered in the present study. ${ }^{28}$

Our clinical study emanated from the desire to apply the principles for prevention of sudden death with amiodarone, first proposed by McKenna et al in $1985,{ }^{21}$ to a community based and unselected patient population with HCM. Because of the initial enthusiasm surrounding the introduction of amiodarone for the drug treatment of patients with HCM perceived to be at increased risk for sudden death because of NSVT, ${ }^{18-21}$ we harboured strong ethical concerns about subjecting such patients to a randomised placebo controlled study design. Therefore, because the present data were assembled in a non-randomised fashion we cannot definitely conclude whether amiodarone was efficacious in reducing HCM related mortality. We nevertheless believe that our data are of value in assessing the role of amiodarone in the management of risk for sudden death in patients with HCM. The present cohort was particularly suitable for assessing amiodarone in this regard, given the fact that our patients were not subjected to tertiary centre referral bias and represent a population more closely resembling the true overall disease spectrum of HCM in the community to which the practising clinician is exposed.

1 Maron BJ, Bonow RO, Cannon RO, et al. Hypertrophic cardiomyopathy: interrelation of clinical manifestations, pathophysiology, and therapy. N Engl f Med 1987;316:780pathophysio: $844-52$.

2 McKenna W, Deanfield J, Faruqui A, et al. Prognosis in hypertrophic cardiomyopathy: role of age and clinical, electrocardiographic and hemodynamic features. Am $\mathcal{F}$ Cardiol 1981;47:532-8

3 Frank S, Braunwald E. Idiopathic hypertrophic subaortic stenosis: clinical analysis of 126 patients with emphasis on the natural history. Circulation 1968;37:759-88.

4 Shah PM, Adelman AG, Wigle ED, et al. The natural (and unnatural) history of hypertrophic obstructive cardiomyopathy. Circ Res 1973;34/35(suppl 2):II-179-95.

5 Wigle ED, Sasson Z, Henderson MA, et al. Hypertrophic cardiomyopathy: the importance of the site and extent of

hypertrophy - a review. Progr Cardiovasc Dis 1985;28:1-83. hypertrophic cardiomyopathy: profile of 78 patients. Circulation 1982;65:1388-94.

7 Swan DA, Bell B, Oakley C, et al. Analysis of symptomatic course and prognosis and treatment of hypertrophic obstructive cardiomyopathy. Br Heart f 1971;33:671-85.

8 Hardarson T, De La Calzada CS, Curiel R, et al. Prognosis and mortality of hypertrophic obstructive cardiomyopathy. Lancet 1973;ii:1462-7.

9 Loogen F, Kuhn H, Gietzen F, et al. Clinical course and prognosis of patients with typical and atypical hypertrophic obstructive and with hypertrophic non-obstructive cardiomyopathy. Eur Heart f 1983;4(suppl F):145-53.

10 Hecht GM, Panza JA, Maron BJ. Clinical course of middleaged asymptomatic patients with hypertrophic cardiomyopathy. Am $\mathcal{F}$ Cardiol 1992;69:935-40.

11 McKenna WJ, Deanfield JE. Hypertrophic cardiomyopathy: an important cause of sudden death. Arch Dis Child 1984; 59:971-5.

12 Fiddler GI, Tajik AJ, Weidman WH, et al. Idiopathic hypertrophic subaortic stenosis in the young. Am f Cardiol 1978; 42:793-9.

13 Cecchi F, Maron BJ, Epstein SE. Long-term outcome of patients with hypertrophic cardiomyopathy successfully resuscitated after cardiac arrest. F Am Coll Cardiol 1989;13: 1283-8.

14 McKenna WJ, Camm AJ. Sudden death in hypertrophic cardiomyopathy: assessment of patients at high risk. Circulation 1989;80:1489-92.

15 McKenna WJ, Counihan PJ, Chikamori T. Sudden death in hypertrophic cardiomyopathy: identification and management of high risk patients. In: Baroldi G, Camerini F, Goodwin JF, eds. Advances in cardiomyopathies. Berlin: Springer-Verlag, 1990:72-80.

16 Watkins H, Rosenzweig A, Hwang D-S, et al. Characteristics and prognostic implications of myosin missense mutations in familial hypertrophic cardiomyopathy. $N$ Engl $f \mathrm{Med}$ in familial hypertrophi

17 Maron BJ, Cecchi F, McKenna WJ. Risk factors and current status of risk stratification profiles for sudden cardiac death in patients with hypertrophic cardiomyopathy. Br Heart $\mathcal{F}$ 1994;72(suppl):S14-18. 
18 Maron BJ, Savage DD, Wolfson JK, et al. Prognostic significance of 24 hour ambulatory electrocardiographic moni-
toring in patients with hypertrophic cardiomyopathy: a toring in patients with hypertrophic cardiom

19 Savage DD, Seides SF, Maron BJ, et al. Prevalence of arrhythmias during 24-hour electrocardiographic monitoring and exercise testing in patients with obstructive and nonobstructive hypertrophic cardiomyopathy. Circulation. 1979;59:866-75.

20 McKenna WJ, England D, Doi YL, et al. Arrhythmia in hypertrophic cardiomyopathy: I. Influence on prognosis. $B r$ Heart $\mathcal{7} 1981 ; 46: 168-72$.

21 McKenna WJ, Oakley CM, Krikler DM, et al. Improved survival with amiodarone in patients with hypertrophic cardiomyopathy and ventricular tachycardia. Br Heart $f$ 1985;53:412-16.

22 Spirito P, Rapezzi C, Autore C, et al. Prognosis of asymptomatic patients with hypertrophic cardiomyopathy and nonsustained ventricular tachycardia. Circulation 1994;90: 2743-7.

23 Cecchi F, Olivotto I, Montereggi A, et al. Hypertrophic cardiomyopathy in Tuscany: clinical course and outcome in an unselec

24 Maron BJ, Spirito P. Impact of patient selection biases on the perception of hypertrophic cardiomyopathy and its natural history. Am $\mathcal{f}$ Cardiol 1993;72:970-2.

25 Shapiro LM, Zezulka A. Hypertrophic cardiomyopathy: a common disease with a good prognosis-five year experience of a district general hospital. Br Heart $f$ 1983;50:530-3.

26 Kofflard MJ, Waldstein DJ, Vos J, et al. Prognosis in hypertrophic cardiomyopathy: long-term follow-up in a large, unselected outpatient population. Am f Cardiol 1993;72. 939-43.

27 Spirito P, Chiarella F, Carratino L, et al. Clinical course and prognosis of hypertrophic cardiomyopathy in an outpatien population. N Engl f Med 1989;320:749-55.

28 Fananapazir L, Leon MB, Bonow RO, et al. Sudden death during empiric amiodarone therapy in symptomatic hyperduring empiric amiodarone therapy in symptomatic hyp

29 McKenna WJ, Harris L, Perez G, et al. Arrhythmia in hypertrophic cardiomyopathy: II. Comparison of amiodarone and verapamil in treatment. Br Heart f 1981;46:173-8.

30 McKenna WJ, Harris L, Rowland E, et al. Amiodarone for long-term management of patients with hypertrophic cardiomyopathy. Am f Cardiol 1984;54:802-10.
31 Maron BJ, Gottdiener JS, Epstein SE. Patterns and significance of distribution of left ventricular hypertrophy in hypertrophic cardiomyopathy: a wide angle, twodimensional echocardiographic study of 125 patients. $A m \mathcal{F}$ Cardiol 1981;48:418-28.

32 Shapiro LM, McKenna WJ. Distribution of left ventricular hypertrophy in hypertrophic cardiomyopathy: a twodimensional echocardiographic study. $7 \mathrm{Am}$ Coll Cardiol 1983;2:437-44

33 Panza JA, Petrone RK, Fananapazir L, et al. Utility of continuous wave Doppler in noninvasive assessment of the left ventricular outflow tract pressure gradient in patients with hypertrophic cardiomyopathy. $\mathcal{F}$ Am Coll Cardiol 1992; 19:91-9.

34 Kaplan E, Meier P. Nonparametric estimation from incomplete observations. $\mathcal{F}$ Am Stat Assoc 1958;53:457-81.

35 Spirito P, Maron BJ, Bonow RO, et al. Occurrence and significance of progressive left ventricular wall thinning and relative cavity dilatation in patients with hypertrophic cardiomyopathy. Am f Cardiol 1987;60:123-9.

36 Frenneaux MP, Counihan PJ, Porter A, et al. Effects of amiodarone on erect and supine exercise haemodynamics and exercise capacity in patients with hypertrophic cardiomyopathy. Eur Heart f 1992;13:687-96.

37 Sugrue DD, Dickie S, Myers MJ, et al. Effect of amiodarone on left ventricular ejection and filling in hypertrophic cardiomyopathy as assessed by radionuclide angiography. Am f Cardiol 1984;54:1054-8.

38 Debbas NMG, du Cailar C, Bexton RS, et al. The QT interval: a predictor of the plasma and myocardial concentrations of amiodarone. Br Heart $\mathcal{f}$ 1984;51:31620.

39 Spirito P, Seidman CE, McKenna WJ, et al. The management of hypertrophic cardiomyopathy. $N$ Engl $\mathcal{f}$ Med 1997;336:775-85.

40 Friedman PL, Stevenson WG. Unsustained ventricular tachycardia- to treat or not to treat? $N$ Engl $\mathcal{F ~ M e d ~}$ 1996;335:1984-5.

41 Singh BN. Amiodarone: historical development and pharmacological profile. Am Heart f 1983;106:788-97.

42 Greene HL. The CASCADE study: randomized antiarrhythmic drug therapy in survivors of cardiac arrest in Seattle: CASCADE Investigators. Am f Cardiol 1993;13: $442-9$ 